\title{
Sequential integration of measurements of navigational position parameters
}

\author{
Andrzej Banachowicz ${ }^{1}$, Adam Wolski ${ }^{2}$ \\ ${ }^{1}$ Department of Artificial Intelligence and Applied Mathematics \\ West Pomeranian University of Technology \\ 49 Żołnierska St., 71-210 Szczecin, Poland \\ e-mail: abanachowicz@wi.zut.edu.pl \\ ${ }^{2}$ Institute of Marine Navigation \\ Maritime University of Szczecin \\ 2 Wały Chrobrego St., 70-500 Szczecin, Poland \\ e-mail: a.wolski@am.szczecin.pl
}

Received: 6 January 2010/Accepted: 12 July 2010

\begin{abstract}
The sequential method of integrating navigational parameters obtained from non-simultaneous navigational measurements is presented. The proposed algorithm of position coordinates estimation is general and includes two modes of data processing - from simultaneous and non-simultaneous measurements. It can be used in hybrid receivers of radionavigation systems integrating non-homogeneous position lines or in integrated navigation systems, particularly in receivers combining the measurements of various satellite navigation systems.
\end{abstract}

Keywords: navigational mathematics, GPS, sequential estimation, maritime navigation

\section{Introduction}

The idea of position coordinates determination from non-simultaneous lines of position has been known since the Middle Ages (in its primitive form). In ocean navigation at that time a line obtained from celestial body setting or rising (usually the Sun) as the longitude was combined with a position line of the Sun culmination as the latitude. There was an interval of a few hours between the moments position lines were determined (the time length depended on latitude and season of the year). In centuries that followed the method was improved as an analytical-plotting method and was used in celestial and terrestrial navigation. The dynamic development of radionavigation after World War Two led to a belief that navigational measurements - with their accuracy at that time and speed of navigating vessels - can be regarded as simultaneous.

In navigation, position determination consists in the identification of coordinates in the adopted coordinate system and reference system. Position coordinates cannot be measured directly, therefore they are indirect measurements. The original measurements involve physical quantities, which are used to determine geometric relations 
between the observer's position and the positions of aids to navigation (lighthouses, radionavigational system stations, navigational satellites orbiting the Earth). Geometric quantities which express the relations between navigational mark coordinates and the measurement point (observer's position) are known as the navigational position parameter $u$, whereas the relation between the navigational parameter and the measurement position in the examined space (coordinate system) is termed the position navigational function $f$.

Traditionally, there has been a tacit assumption in navigational algorithms (Farrel et al., 1999; Mitchell, 2007; Parkinson et al., 1996; Rogers, 2003) that measurements of navigational position parameters are made simultaneously, although in many cases this assumption is not justified.

In practice, one always has to do with non-simultaneous measurements of navigational parameters. This is due to:

- movement of the ship (sensor, receiver),

- movement of an aid to navigation (e.g. satellite),

- technical conditions (operation of a radionavigational system station in a chain, single-channel measurement path of the receiver, sequential measurement cycle, asynchronous measurements from individual navigational devices).

Traditional navigational methods of position determination are based on an assumption that navigational parameters are measured simultaneously, or it is assumed that errors due to non-simultaneity are negligibly small. One exception to this is the position determination from non-simultaneous position lines in terrestrial and celestial navigation, where the time between measurement moments is considerable.

However, in accurate automated or integrated navigation even small time intervals (several seconds, depending on the precision of dead reckoning navigation) translate into essential errors of coordinates position or estimator instability. Therefore, algorithms of navigational data processing should take account of non-simultaneity of measurements.

\section{Determination of position coordinates from simultaneous measurements of navigational parameters}

The simplest practical case of position coordinates determination is the calculation of coordinates from simultaneously measured navigational parameters. In the general case of position coordinate calculations we have a navigational vector function mapping navigational space elements into the space of measurements. This function can be written as the following vector mapping:

$$
\text { f : } R^{m} \supset N \rightarrow U \subset R^{n}, n \geq m
$$

where $R, N$, and $U$ are real space, navigational space, measurement space, respectively; $m$ and $n$ are dimensions of navigational space and measurement space, respectively.

The mapping will be put in a form of the system of equations 


$$
\begin{gathered}
f_{1}\left(x_{1}, x_{2}, \ldots, x_{m}\right)-u_{1}=0 \\
f_{2}\left(x_{1}, x_{2}, \ldots, x_{m}\right)-u_{2}=0 \\
\ldots \ldots \ldots . \ldots . \ldots . \ldots . . . . . . \\
f_{n}\left(x_{1}, x_{2}, \ldots, x_{m}\right)-u_{n}=0
\end{gathered}
$$

where $x_{i}$ is the $i$-th coordinate of position, and $u_{i}$ is the measured navigational parameter (bearing, range difference, pseudo-range).

The system of equations (2) in the vector notation will have this form

$$
\mathbf{f}(\mathbf{x})-\mathbf{u}=\mathbf{0}
$$

where $\mathbf{x}=\left[x_{1}, x_{2}, \ldots, x_{m}\right]^{T}$ is a generalized vector of position coordinates (state vector), depending on the assumed coordinate system $(X, Y, Z, \Delta t$ or $\varphi \operatorname{sg} \lambda \mathrm{s} h, \Delta t), \mathbf{x} \in N$, and $\mathbf{u}=\left[u_{1}, u_{2}, \ldots, u_{n}\right]^{T}$ is the vector of measured navigational parameters, $\mathbf{u} \in U$.

There are two cases of solving the equation (3). One is deterministic, where the number of position parameters measurements is equal to the number of estimated coordinates, i.e. $n=m$. In this case, the equation (3) is solved by Newton's method for non-linear equation systems (Demidovich, 1987). In the $(k+1)$-th step the position coordinate vector will be expressed by the formula

$$
\mathbf{x}^{(k+1)}=\mathbf{x}^{(k)}+\mathbf{G}^{-1}\left(\mathbf{x}^{(k)}\right) \mathbf{z}^{(k)}
$$

where $\mathbf{z}$ - measurement vector, the difference between the measured navigational parameters

and the vector of projected (estimated) measurements; this vector is defined by the relation:

$$
\mathbf{z}^{(k)}=\mathbf{u}-\mathbf{f}\left(\mathbf{x}^{(k)}\right)
$$

and $\mathbf{G}$ is the Jacobian matrix of the mapping $\mathbf{f}$ (navigational position function).

The other case occurs when the number of position parameter measurements is greater than the number of coordinates to be determined $(n>m)$; then the equation (3) is solved using the least squares method. In this case in $(k+1)$-th step one obtains the following approximation:

$$
\mathbf{x}^{(k+1)}=\mathbf{x}^{(k)}+\left[\mathbf{G}^{\mathrm{T}}\left(\mathbf{x}^{(k)}\right) \mathbf{P}_{\mathbf{u}}^{-1} \mathbf{G}\left(\mathbf{x}^{(k)}\right)\right]^{-1} \mathbf{G}^{\mathrm{T}}\left(\mathbf{x}^{(k)}\right) \mathbf{P}_{\mathbf{u}}^{-1} \mathbf{z}^{(k)}
$$

where $\mathbf{P}_{u}$ is the covariance matrix of the vector of measured position parameters $\mathbf{u}$.

The vector $\mathbf{z}$ is defined by the formula (5). Formally, the matrix $\mathbf{P}_{u}$ is the covariance matrix of the vector $\mathbf{z}$. As this vector is the difference of vectors according to the relation (5), and the vector $\mathbf{f}(\mathbf{x})$ being the result of calculations is determined with any accuracy (non-random vector), then one can assume that the covariance matrix of the vector $\mathbf{u}$ is equal to the covariance matrix of the vector $\mathbf{z}$.

Calculations are further continued through subsequent iterations, until the assumed accuracy of coordinates is reached. If the iteration process (4) or (6) is convergent with 
the real solution $\mathbf{x}$, then the estimation of accuracy of calculated position coordinates is approximately equal to the value of the second addend in (4) or (6) calculated in the final step. This fact is often used for the evaluation of iteration process stop. The estimated position or previous fix is usually adopted as the first approximation. In both cases, i.e. Newton's method or the least squares method, the covariance matrix of the state vector $\mathbf{x}$ (position coordinates) is calculated from the following formula (Banachowicz, 1994)

$$
\mathbf{P}_{\mathbf{x}}=\left[\mathbf{G}^{\mathrm{T}}\left(\mathbf{x}^{(k)}\right) \mathbf{P}_{\mathbf{u}}^{-1} \mathbf{G}\left(\mathbf{x}^{(k)}\right)\right]^{-1}
$$

\section{Determination of position coordinates from non-simultaneous measurements of navigational parameters}

Due to the length of measurement cycles or delay in data distribution and transmission, principally measurements are not performed simultaneously. In the case of measurement non-simultaneity one can apply the sequential method of joining measurements, which consists in projecting values the measurements will have at a common time. This is essentially similar to known methods used in terrestrial or celestial navigation, where position lines are brought down to a common time.

Let us choose a series of moments $t_{1}<t_{2}<\ldots<t_{n}$ (after bringing them down to a common time scale, if necessary), where $t_{i}$ denotes the moment of $i$-th measurement of a navigational parameter. For convenience let us adopt that the measurements will be brought down to the last moment of measurement (then the coordinates of the current position will be obtained). The projected vector of measured navigational position parameters $\mathbf{u}_{p}$ can be calculated from the relation

$$
\mathbf{u}_{p}=\mathbf{u}+\Delta \mathbf{u}
$$

where

- vector of projected increments of navigational position parameters values

$$
\begin{gathered}
\Delta \mathbf{u}=\sum_{i=1}^{n} \Delta \mathbf{u}_{i} \\
\Delta \mathbf{u}_{i}=\mathbf{e}_{i}^{\mathrm{T}} \cdot \operatorname{grad} f_{i} \cdot \Delta \mathbf{x}^{(i)}
\end{gathered}
$$

- vector of the canonical base of $n$-dimensional space of measurements ( 1 occurs in an $i$-th position, corresponding to a given coordinate in the space of measurements)

$$
\mathbf{e}_{i}=[0,0, \ldots, 0,1,0, \ldots, 0]
$$

- gradient of $i$-th navigational function (position line, plane or hypersurface), it is an $i$-th row of the matrix $\mathbf{G}$ 


$$
\operatorname{grad} f_{i}=\left[\frac{\partial f_{i}}{\partial x_{1}}, \frac{\partial f_{i}}{\partial x_{2}}, \ldots, \frac{\partial f_{i}}{\partial x_{m}}\right]
$$

- vector of value changes in position coordinates between the moment of navigational parameter measurement $t_{i}$ and the common time $t_{n}$

$$
\Delta \mathbf{x}_{i}=\left[\Delta x_{1_{i}}, \Delta x_{2_{i}}, \ldots, \Delta x_{m_{i}}\right]^{\mathrm{T}}
$$

Assume that in sufficiently short time intervals navigational position parameters change linearly. Putting (8) to (5) then to (4) one obtains the formula for $(k+1)$-th approximation of the position coordinates vector in the Newton's method

$$
\mathbf{x}^{(k+1)}=\mathbf{x}^{(k)}+\mathbf{G}^{-1}\left(\mathbf{x}^{(k)}\right)\left[\mathbf{u}+\Delta \mathbf{u}-\mathbf{f}\left(\mathbf{x}^{(k)}\right)\right]
$$

Similar procedure will be followed when using the least squares method. Having substituted (8) to (5) and the substitution result to (6) one gets

$$
\mathbf{x}^{(k+1)}=\mathbf{x}^{(k)}+\left[\mathbf{G}^{\mathrm{T}}\left(\mathbf{x}^{(k)}\right) \mathbf{P}_{p}^{-1} \mathbf{G}\left(\mathbf{x}^{(k)}\right)\right]^{-1} \mathbf{G}^{\mathrm{T}}\left(\mathbf{x}^{(k)}\right) \mathbf{P}_{p}^{-1}\left[\mathbf{u}+\Delta \mathbf{u}-\mathbf{f}\left(\mathbf{x}^{(k)}\right)\right] .
$$

From the theorem on the mean value and the covariance matrix of constant matrices multiplied by random vector (Banachowicz, 2006) one obtains the following formulae for mean vector value of position coordinates increments (initial approximation in iterations is adopted with any small errors):

$$
\begin{gathered}
\Delta \mathbf{x}_{\text {mean }}^{(k)}=\mathbf{G}^{-1}\left(\mathbf{x}^{(k)}\right) \mathbf{z}_{p}^{(k)} \\
\mathbf{P}_{\mathbf{x}}=\left[\mathbf{G}^{\mathrm{T}}\left(\mathbf{x}^{(k)}\right) \mathbf{P}_{p}^{-1} \mathbf{G}\left(\mathbf{x}^{(k)}\right)\right]^{-1}
\end{gathered}
$$

where $\mathbf{z}_{p}$ is the projected vector of measurements

$$
\mathbf{z}_{p}^{(k)}=\mathbf{u}_{p}-\mathbf{f}\left(\mathbf{x}^{(k)}\right)
$$

The covariance matrix $\mathbf{P}_{p}$ of the projected vector of measured navigational position parameters, as per formulae (8), (9) and (10) is expressed as

$$
\mathbf{P}_{p}=\mathbf{P}_{\mathbf{u}}+\sum_{i=1}^{n} \mathbf{P}_{\Delta \mathbf{u}_{i}}+\sum_{i=1}^{n}\left(\mathbf{P}_{\mathbf{u} \Delta \mathbf{u}_{i}}+\mathbf{P}_{\mathbf{u} \Delta \mathbf{u}_{i}}^{\mathrm{T}}\right)+\sum_{\substack{i=1 \\ i \neq j}}^{n} \sum_{j=1}^{n} \mathbf{P}_{\Delta \mathbf{u}_{i} \Delta \mathbf{u}_{j}}
$$

with the covariance matrix $\sum_{i=1}^{n} \mathbf{P}_{\Delta \mathbf{u}_{i}}$ of increment values of navigational position parameters

$$
\sum_{i=1}^{n} \mathbf{P}_{\Delta \mathbf{u}_{i}}=\sum_{i=1}^{n} \mathbf{e}_{i}^{\mathrm{T}} \cdot \operatorname{grad} f_{i} \cdot \mathbf{P}_{\Delta \mathbf{x}_{i}}\left(\operatorname{grad} f_{i}\right)^{\mathrm{T}} \cdot \mathbf{e}_{i}
$$

and 
- $\mathbf{P}_{\Delta \mathbf{x}_{i}}$ - covariance matrix of coordinates increments,

- $\sum_{i=1}^{n} \mathbf{P}_{\mathbf{u} \Delta \mathbf{u}_{i}}$ - covariance matrix between the vector of measured navigational position parameters and the vector of their increments (cross covariance matrix of two random vectors (Banachowicz, 2006; Vaniček et al., 1986)),

- $\sum_{\substack{i=1 \\ i \neq j}}^{n} \mathbf{P}_{\Delta \mathbf{u}_{i} \Delta \mathbf{u}_{j}}$ - covariance matrix between individual increments of measured navigational position parameters values (cross covariance matrix of two random vectors)

$$
\mathbf{P}_{\Delta \mathbf{u}_{i} \Delta \mathbf{u}_{j}}=\mathbf{e}_{i}^{\mathrm{T}} \cdot \operatorname{grad} f_{i} \cdot \mathbf{P}_{\Delta \mathbf{x}_{i} \Delta \mathbf{x}_{j}}\left(\operatorname{grad} f_{j}\right)^{\mathrm{T}} \cdot \mathbf{e}_{j}
$$

- $\mathbf{P}_{\Delta \mathbf{x}_{i} \Delta \mathbf{x}_{j}}$ - cross covariance matrix of coordinates increments.

The equation (19) describes the covariance matrix of the projected measurement vector. That matrix is increased in relation to the measurement vector matrix by the covariance matrix of projected increments of navigational parameters values and the covariance matrix between measurements and their projections. If the total distribution of measurement vectors and navigational parameters increment projections is normal, then, with a natural assumption that navigational parameters measurement errors and estimation (projections are based on this assumption) are independent, then the third addend on the right-hand side of the equation (19) is a zero vector. Finally, one can obtain the following formula for the covariance matrix of fix coordinates from non-simultaneous measurements of navigational position parameters:

$$
\mathbf{P}_{p}=\mathbf{P}_{\mathbf{u}}+\sum_{i=1}^{n} \mathbf{P}_{\Delta \mathbf{u}_{i}}+\sum_{\substack{i=1 \\ i \neq j}}^{n} \sum_{j=1}^{n} \mathbf{P}_{\Delta \mathbf{u}_{i} \Delta \mathbf{u}_{j}}
$$

\section{Sequential integration of measurements from two positioning systems}

Let us illustrate the above considerations with an example. For this purpose we will assume that two different positioning systems are being integrated:

- satellite GPS system,

- another satellite pseudo-range system.

Let us assume that all the measurements are made sequentially. Then the individual vectors and matrices take the form

- state vector

$$
\mathbf{x}=\left[\varphi, \lambda, h, \Delta t_{I}, \Delta t_{I I}\right]^{\mathrm{T}}
$$

where $\varphi \mathrm{s} \lambda \mathrm{s} h$ are geodetic latitude, geodetic longitude, and geodetic (ellipsoidal) height, respectively; $\Delta t_{I}$ and $\Delta t_{I I}$ are clock errors of the GPS receiver, and of another pseudo-range system, respectively, 
vector of measurements ( $k$ pseudo-range measurements of the first system and $m$ measurements of the second system)

$$
\mathbf{z}_{p}=\left[\begin{array}{c}
d_{1}+\frac{\partial d_{1}}{\partial \varphi} \Delta \varphi_{1}+\frac{\partial d_{1}}{\partial \lambda} \Delta \lambda_{1}+\frac{\partial d_{1}}{\partial h} \Delta h_{1}-d_{z_{1}} \\
d_{2}+\frac{\partial d_{2}}{\partial \varphi} \Delta \varphi_{2}+\frac{\partial d_{2}}{\partial \lambda} \Delta \lambda_{2}+\frac{\partial d_{2}}{\partial h} \Delta h_{2}-d_{z_{2}} \\
\ldots \\
d_{k}+\frac{\partial d_{k}}{\partial \varphi} \Delta \varphi_{k}+\frac{\partial d_{k}}{\partial \lambda} \Delta \lambda_{k}+\frac{\partial d_{k}}{\partial h} \Delta h_{k}-d_{z_{k}} \\
d_{k+1}+\frac{\partial d_{k+1}}{\partial \varphi} \Delta \varphi_{k+1}+\frac{\partial d_{k+1}}{\partial \lambda} \Delta \lambda_{k+1}+\frac{\partial d_{k+1}}{\partial h} \Delta h_{k+1}-d_{z_{k+1}} \\
d_{k+2}+\frac{\partial d_{k+2}}{\partial \varphi} \Delta \varphi_{k+2}+\frac{\partial d_{k+2}}{\partial \lambda} \Delta \lambda_{k+2}+\frac{\partial d_{k+2}}{\partial h} \Delta h_{k+2}-d_{z_{k+2}} \\
\ldots \\
d_{k+m}+\frac{\partial d_{k+m}}{\partial \varphi} \Delta \varphi_{k+m}+\frac{\partial d_{k+m}}{\partial \lambda} \Delta \lambda_{k+m}+\frac{\partial d_{k+m}}{\partial h} \Delta h_{k+m}-d_{z_{k+m}}
\end{array}\right]
$$

where

$d_{i}$ - measured $i$-th pseudo-range,

$d_{z_{i}}$ - calculated $i$-th pseudo-range,

$\Delta \varphi_{i}, \Delta \lambda_{i}, \Delta h_{i}$-increments of geodetic coordinates between $i$-th and $n$-th moment (one to which all measurements are brought down), obtained from estimation, $\frac{\partial d_{i}}{\partial \varphi}, \frac{\partial d_{i}}{\partial \lambda}, \frac{\partial d_{i}}{\partial h}-$ partial derivatives of $i$-th pseudo-range (navigational function) relative to geodetic coordinates,

$k$ - number of measurements from the of GPS system (GPS),

$m$ - number of measurements from another pseudo-range navigational system, Jacobian matrix of navigational position function

$$
\mathbf{G}=\left[\begin{array}{ccccc}
\frac{\partial d_{1}}{\partial \varphi} & \frac{\partial d_{1}}{\partial \lambda} & \frac{\partial d_{1}}{\partial h} & \frac{\partial d_{1}}{\partial \Delta t_{I}} & 0 \\
\cdots & \cdots & \cdots & \cdots & \ldots \\
\frac{\partial d_{k}}{\partial \varphi} & \frac{\partial d_{k}}{\partial \lambda} & \frac{\partial d_{k}}{\partial h} & \frac{\partial d_{k}}{\partial \Delta t_{I}} & \\
\frac{\partial d_{k+1}}{\partial \varphi} & \frac{\partial d_{k+1}}{\partial \lambda} & \frac{\partial d_{k+1}}{\partial h} & 0 & \frac{\partial d_{k+1}}{\partial \Delta t_{I I}} \\
\cdots & \cdots & \cdots & \cdots & \cdots \\
\frac{\partial d_{k+m}}{\partial \varphi} & \frac{\partial d_{k+m}}{\partial \lambda} & \frac{\partial d_{k+m}}{\partial h} & 0 & \frac{\partial d_{k+m}}{\partial \Delta t_{I I}}
\end{array}\right]
$$

covariance matrix of measurement vector (assuming the both systems are independent) 


$$
\mathbf{P}_{\mathbf{u}}=\left[\begin{array}{cccccc}
\sigma_{d_{1}}^{2} & \cdots & \sigma_{d_{1} d_{k}} & 0 & \cdots & 0 \\
\cdots & \cdots & \cdots & \cdots & \cdots & \cdots \\
\sigma_{d_{1} d_{k}} & \cdots & \sigma_{d_{k}}^{2} & 0 & \cdots & 0 \\
0 & 0 & 0 & \sigma_{d_{k+1}}^{2} & \cdots & \sigma_{d_{k+1} d_{k+m}} \\
\cdots & \cdots & \cdots & \cdots & \cdots & \cdots \\
0 & 0 & 0 & \sigma_{d_{k+1} d_{k+m}} & \cdots & \sigma_{d_{k+m}}^{2}
\end{array}\right]
$$

where $\sigma_{d_{i}}^{2}$ is a variance of pseudo-range $d_{i}, \sigma_{d_{i} d_{j}}$ is a covariance between pseudo-ranges $d_{i}$ and $d_{j}$.

If both systems are dependent (or correlated only), then their mutual correlation should be taken into account in the matrix $\mathbf{P}_{u}$.

covariance matrix of coordinates increments (practically it is a covariance matrix of estimated position coordinates increments)

$$
\mathbf{P}_{\Delta \mathbf{x}_{i}}=\left[\begin{array}{ccccc}
\sigma_{\Delta \varphi_{i}}^{2} & \sigma_{\Delta \varphi_{i} \Delta \lambda_{i}} & \sigma_{\Delta \varphi_{i} \Delta h_{i}} & \sigma_{\Delta \varphi_{i} \Delta t_{i}} & \sigma_{\Delta \varphi_{i} \Delta t_{I_{i}}} \\
\sigma_{\Delta \varphi_{i} \Delta \lambda_{i}} & \sigma_{\Delta \lambda_{i}}^{2} & \sigma_{\Delta \lambda_{i} \Delta h_{i}} & \sigma_{\Delta \lambda_{i} \Delta t_{i}} & \sigma_{\Delta \varphi_{i} \Delta t_{I_{i}}} \\
\sigma_{\Delta \varphi_{i} \Delta h_{i}} & \sigma_{\Delta \lambda_{i} \Delta h_{i}} & \sigma_{\Delta h_{i}}^{2} & \sigma_{\Delta h_{i} \Delta t_{I_{i}}} & \sigma_{\Delta h_{i} \Delta t_{I_{i}}} \\
\sigma_{\Delta \varphi_{i} \Delta t_{I_{i}}} & \sigma_{\Delta \lambda_{i} \Delta t_{I_{i}}} & \sigma_{\Delta h_{i} \Delta t_{I_{i}}} & \sigma_{\Delta t_{I_{i}}}^{2} & \sigma_{\Delta t_{I_{i}} \Delta t_{I_{i}}} \\
\sigma_{\Delta \varphi_{i} \Delta t_{I_{i}}} & \sigma_{\Delta \lambda_{i} \Delta t_{I_{i}}} & \sigma_{\Delta h_{i} \Delta t_{I_{i}}} & \sigma_{\Delta t_{I_{i}} \Delta t_{I_{i}}} & \sigma_{\Delta t_{I_{i}}}^{2}
\end{array}\right]
$$

covariance matrix between individual value increments of measured navigational position parameters

$$
\mathbf{P}_{\Delta \mathbf{x}_{i} \Delta \mathbf{x}_{j}}=\left[\begin{array}{ccccc}
\sigma_{\Delta \varphi_{i} \Delta \varphi_{j}} & \sigma_{\Delta \varphi_{i} \Delta \lambda_{j}} & \sigma_{\Delta \varphi_{i} \Delta h_{j}} & \sigma_{\Delta \varphi_{i} \Delta t_{I_{j}}} & \sigma_{\Delta \varphi_{i} \Delta I_{I_{j}}} \\
\sigma_{\Delta \lambda_{i} \Delta \varphi_{j}} & \sigma_{\Delta \lambda_{i} \Delta \lambda_{j}} & \sigma_{\Delta \lambda_{i} \Delta h_{j}} & \sigma_{\Delta \lambda_{i} \Delta t_{I_{j}}} & \sigma_{\Delta \lambda_{i} \Delta t_{I_{j}}} \\
\sigma_{\Delta h_{i} \Delta \varphi_{j}} & \sigma_{\Delta h_{i} \Delta \lambda_{j}} & \sigma_{\Delta h_{i} \Delta h_{j}} & \sigma_{\Delta h_{i} \Delta t_{I_{j}}} & \sigma_{\Delta h_{i} \Delta t_{I_{j}}} \\
\sigma_{\Delta t_{I_{i}} \Delta \varphi_{j}} & \sigma_{\Delta t_{t_{i}} \Delta \lambda_{j}} & \sigma_{\Delta t_{I_{i}} \Delta h_{j}} & \sigma_{\Delta t_{I_{i}} \Delta t_{I_{j}}} & \sigma_{\Delta t_{I_{i}} \Delta I_{I_{j}}} \\
\sigma_{\Delta t_{I_{i}} \Delta \varphi_{j}} & \sigma_{\Delta t_{I_{i}} \Delta \lambda_{j}} & \sigma_{\Delta t_{I_{i}} \Delta h_{j}} & \sigma_{\Delta t_{I_{i}} \Delta t_{I_{j}}} & \sigma_{\Delta t_{I_{i}} \Delta t_{I I_{j}}}
\end{array}\right]
$$

\section{Summary}

The presented method of position coordinates calculations based on data from nonsimultaneous measurements of navigational position parameters can be used in integrated navigational systems or hybrid receivers of radionavigation systems, e.g. GPS/GALILEO, GPS/GLONASS, GPS/rho-rho system or another radionavigation system.

By extending the concept of navigational parameter measurement vector to the projected measurement vector one can standardize algorithms for calculations of a fix coordinates. The application of projected values of navigational parameters, in turn, 
enables determining a position using any set of position parameters - homogenous or non-homogenous. This is essential to automated navigational systems where measurements of navigational parameters are integrated. Projected values in non-simultaneous measurements are burdened with larger errors than simultaneous measurements. This, however, is accounted for in the resultant position covariance matrix. Then a non-biased assessment of position coordinates is obtained, that is correct from the viewpoint of the system measurement model (Banachowicz, 1994; Banachowicz, 2005a; Banachowicz et al., 2005b). The algorithm of position coordinates calculation from non-simultaneous measurements is more general, and when simultaneous measurements are made it is simplified to the first algorithm step.

\section{Acknowledgments}

The study has been performed within the statutory research of Maritime University of Szczecin on 'Problems of navigational safety of sea-going vessels' in co-operation with West Pomeranian University of Technology in Szczecin.

\section{References}

Banachowicz A., (1994): Błąd systematyczny wspótrzędnych pozycji w przypadku wykorzystania minimalnej liczby pomiarów nawigacyjnych, Geodezja i Kartografia, Warsaw, Vol. XLIII, No 2, pp. 109-119.

Banachowicz A., (2005): Określanie wspótrzędnych pozycji z niejednoczesnych pomiarów parameterów nawigacyjnych, Prace Wydziału Nawigacyjnego Akademii Morskiej, No 17, Gdynia. pp. 5-15.

Banachowicz A., Uriasz J., (2005): The Running Fix, European Journal of Navigation, Vol. 3, No 4, November, pp. 60-64.

Banachowicz A., (2006): Uogólnione prawo przenoszenia błędów losowych, Prace Wydziału Nawigacyjnego Akademii Morskiej w Gdyni Nr 18, Gdynia, pp. 5-16.

Demidovich B.P., Maron I.A., (1987): Computational Mathematics, Mir Publisher, Moscow.

Farrell J.A., Barth M., (1999): The Global Positioning System and Inertial Navigation, McGraw-Hill, New York.

Mitchell H.B., (2007): Multi-Sensor Data Fusion. An Introduction, Springer, Berlin, Heidelberg, New York.

Parkinson B.W., Spilker J.J.(Jr), (1996): Global Positioning System: Theory and Applications, Vol. I and II, Publisher by AIAA, Washington.

Rogers R.M., (2003): Applied Mathematics in Integrated Navigation Systems, $2^{\text {nd }}$ Edition, AIAA, Reston, Virginia.

Vaniček P., Krakiwsky E.J., (1986): Geodesy: the concepts, $2^{\text {nd }}$ Edition, North Holland, Amsterdam. 
Sekwencyjna metoda integracji pomiarów nawigacyjnych systemów satelitarnych

\section{Andrzej Banachowicz ${ }^{1}$, Adam Wolski ${ }^{2}$}

${ }^{1}$ Katedra Metod Sztucznej Inteligencji i Matematyki Stosowanej

Zachodniopomorski Uniwersytet Technologiczny w Szczecinie

ul. Żołnierska 49, 71-210 Szczecin

e-mail: abanachowicz@wi.zut.edu.pl

${ }^{2}$ Instytut Nawigacji Morskiej

Akademia Morska w Szczecinie

Wały Chrobrego 2, 70-500 Szczecin

e-mail: a.wolski@am.szczecin.pl

\section{Streszczenie}

W artykule przedstawiono sekwencyjną metodę integracji parametrów nawigacyjnych pochodzących z niejednoczesnych pomiarów nawigacyjnych. Zaproponowany w niej algorytm estymacji współrzędnych pozycji jest ogólny i zawiera w sobie dwa przypadki opracowywania pomiarów - jednoczesnych i niejednoczesnych. Może on być wykorzystany w hybrydowych odbiornikach systemów radionawigacyjnych integrujących niejednorodne linie pozycyjne lub w zintegrowanych systemach nawigacyjnych, a w szczególności w odbiornikach łączących pomiary różnych nawigacyjnych systemów satelitarnych. 